\section{ASSESSING PERSONAL STRENGTHS OF JAPANESE WORKERS - A PRELIMINARY STUDY}

Y Otsuka*. University of Tsukuba, Tokyo, Japan

\subsection{6/oemed-2018-ICOHabstracts. 1758}

Introduction Recognising our strengths and using them in our daily lives is essential for improving our well-being. Recently this approach has been applied to work settings. Strengths Finder (SF) and Values in Action Inventory of Strengths (VIAIS) are the most commonly used international instruments. However, these instruments were originally developed in Western countries and it is not certain whether the subordinate concepts of these instruments are suitable for people in the East. Therefore, this study was designed to develop an instrument for assessing the personal strengths of Japanese workers. Methods All concepts within SF and VIA-IS and several other concepts that emerged as a result of brainstorming conducted by occupational health professionals in Japan were considered as subscales of the developing instrument. Thirty-three concepts were elicited, and subordinate items of each concept were developed. Of these, one concept was considered ambiguous, and therefore, 32 concepts with 264 items were used in the preliminary instrument. This was distributed to Japanese workers $(n=971)$ between July and November 2011. After excluding 122 participants with missing responses, the data of the remaining 849 participants were used in the analyses.

Results After excluding 55 items that showed low factor loadings for each factor, 209 items were used for checking the reliability and validity of the new scale. Cronbach's alpha mostly ranged from 0.64 to 0.84 , except for one concept, 'Shin' (believe), which showed a Cronbach's alpha score of 0.54. Moreover, factorial validity using confirmatory factor analyses revealed that most goodness of fit indices were within acceptable range (CFI: 0.78 to 0.99 , SRMR 0.02 to 0.07 ).

Conclusion A new strengths instrument was developed through discussions with occupational health professionals and a preliminary study with Japanese workers. However, future studies are warranted because several concepts used in the instrument showed insufficient reliability or validity.

\section{STRESS SAFETY NET - A MODEL FOR COMPREHENSIVE ORGANISATIONAL STRESS MANAGEMENT}

${ }^{1}$ GV Prabhu*, ${ }^{2}$ BUdaya Kumar Reddy. 'Advisor (Medical and OHSE), Goa Shipyard Limited, Vasco da gama, Goa; ${ }^{2}$ President, International Stress Management Association, Hyderabad, India

\subsection{6/oemed-2018-ICOHabstracts. 1759}

Introduction Stress in the workplace has emerged as a significant and universal problem in terms of negative health, loss in productivity and socio-economic turbulence. Latest research concludes that integrated stress management (systems approach) showed benefits both to individuals and organisations. It will help to identify the scope of primary, secondary and tertiary interventions in a given organisation in handling stress to gain overall organisational effectiveness. Against this backdrop, Stress Safety Net, a comprehensive model was conceptualised and tested for its efficacy.

Methods An experimental study was conducted on 1000 employees in two different workplace settings in two major companies and in each workplace 500 employees participated in the study. Pre and post test was conducted to verify the efficacy of Stress Safety Net Model. Physiological, Bio-chemical, Psychological and Organisational parameters of stress were tested. Data were analysed using SPSS.

Results Employees perceived distress was significantly reduced. Bio-chemical parameters i.e. Total Cholesterol and LDL have dropped very significantly $(\mathrm{p}<0.001)$. Other parameters such as Serum Cortisol, Orthostatic Tolerance Test (OTT) and Creactive protein (CRP) which are indirect measures of stress showed a significant decrease with $(\mathrm{p}<0.01), \quad(\mathrm{p}<0.05)$ and $(\mathrm{p}<0.05)$ respectively. Overall Role Stress reduced significantly $(\mathrm{p}<0.05)$. Organisational level variables i.e. Management competencies and psychosocial safety climate were improved significantly.

Conclusion Stress Safety Net (a set of well-defined practices, policies, and competencies) implemented by the organisations that helped to identify and overcome stress triggers, promote stress resilience thus enabled employees to execute their task/ deliveries efficiently. The findings demonstrated the efficacy stress safety net model enabled the systems approach in stress management at the workplace.

\section{WORK ORGANISATION AS THE MAIN DETERMINANT OF WORKPLACE BULLYING: AN EPIDEMIOLOGICAL AND AETIOLOGICAL APPROACH}

${ }^{1}$ Fernando Feijo, ${ }^{2}$ Eduarda Buriol, ${ }^{3}$ Cristiane Bunchen, ${ }^{2}$ Paulo Antonio Oliveira, ${ }^{3}$ Mayte Amazarray. ${ }^{1}$ Federal University Of Pelotas, Pelotas, Brazil; ${ }^{2}$ Federal University of Rio Grande do Sul, Porto Alegre, Brazil; ${ }^{3}$ Federal University of Health Sciences, Porto Alegre, Brazil

\subsection{6/oemed-2018-ICOHabstracts. 1760}

Introduction Workplace bullying has been currently described as one of the main psychosocial factors at work that reflects in workers' health. Its determination has been increasingly discussed in literature. We aimed to evaluate the association between work organisation and bullying in a Brazilian Civil Servants sample, in order to understand this phenomenon.

Methods Cross-sectional study with a sample of 2073 workers from the Brazilian Federal Judiciary. Work Context Assessment Scale (EACT) was used to evaluate dimensions of work organisation (OT), working conditions (CT) and interpersonal relationships (RSS). The Negative Acts Questionnaire (NAQ-r) was used to measure bullying. Poisson and logistic regression models were used to test associations of interest, controlling for confounders.

Results The overall prevalence of bullying (exposure to a weekly negative act) was $17.0 \%$. In the regression analyses controlling for social, demographic and occupational confounders, all factors of the work context, when classified as severe, were strongly associated with bullying $(\mathrm{p}<0.01)$, increasing the prevalence of the outcome in 10.4 (OT), 3.6 (CT) and 11.0 (RS) times. After including working context as a covariate in the model, in order to verify the isolated effect of each dimension, severe OT and RS remained strongly associated with bullying (Prevalence ratio $=4.8$ and 6.5, respectively, $\mathrm{p}<0.01)$.

Discussion These findings corroborate the hypothesis that work organisation is one of the main determinants of workplace bullying. Labour characteristics of this public service and the quality of instruments support an adequate temporality between exposure and outcome. Interventions to eliminate bullying and protect workers health should focus on work organisation and work processes. 
997

WORKERS' HEALTHY WEIGHT MANAGEMENT PROGRAM IN A PUBLIC HYDROELECTRIC POWER PLANT IN BRAZIL

${ }^{1}$ FC Schveitzer*, ${ }^{1}$ DPA Leon, ${ }^{2}$ AS Dernis, ${ }^{3}$ AAG Conceição. 'Itaipu Binacional, Foz do Iguaçu, Brazil; 'Itaipu Binacional, Curitiba, Brazil; ${ }^{3}$ SESI Paraná, Curitiba, Brazil

10.1136/oemed-2018-ICOHabstracts.1761

Introduction Noncommunicable diseases associated with obesity are relevant sources of morbidity and mortality worldwide and in Brazil. Companies, through quality of life programs, may influence workers' lifestyle positively reducing modifiable behavioural risk factors. The objective of this study is to describe a workers' healthy weight program in a public company in Brazil.

Methods An intervention study was carried out in a hydroelectric power plant in Brazil between June 2016 and May 2017 with workers that presented obesity or diabetes diagnostics registered in occupational health records. From 1232 workers, 294 were diagnosed and 158 were invited to participate in the first edition of the program. The program realised a regular interdisciplinary approach with medical, nutritional, nursing and physical education professional, and offered gym for practical exercises. The initial and final body composition of the participants who completed the program were compared by bioelectrical impedance analysis, considering weight, muscle mass and fat mass.

Result From 158 invitations, 142 workers accepted and 82 $(57.7 \%)$ completed the program. About the workers who completed the program: $66(80.4 \%)$ reduced their total weight, with an average of $3.56 \mathrm{~kg}$ and a median of $2.6 \mathrm{~kg} ; 60$ (73\%) reduced body fat mass, with an average of $3.8 \mathrm{~kg}$ and a median of $2.7 \mathrm{~kg}$; $21(25.6 \%)$ gained fat mass, with an average of $1.4 \mathrm{~kg}$ and a median of $0.9 \mathrm{~kg}$; and $48.7 \%$ maintained or increased muscle mass. Associated with the quantitative results, the health professionals involved noticed that motivation increased among the participants to achieve a healthier lifestyle.

Discussion The program contributed to weight loss and adoption of healthier habits, reducing modifiable behavioural risk factors for most participants. The quality of life programs in companies provide a friendly environment to change the workers' habits, and also stimulate their co-workers, family and friends to adopt a healthier lifestyle.

\section{Young Workers and Child Labour}

\section{PROTECTING YOUNG WORKERS FROM PSYCHOLOGICAL AND PHYSICAL HAZARDS IN INFORMAL AND SMALL- SCALE WORKPLACES}

\footnotetext{
${ }^{1}$ Susan Gunn*, ${ }^{2}$ Nicholas Levintow. ${ }^{1} \mathrm{Co}$-Chair of the $\mathrm{ICOH}$ Working Group on Young Workers and Child Labour. France; ${ }^{2}$ Chief Technical Officer, SafeYouth@Work project, International Labour Organisation, Switzerland
}

\subsection{6/oemed-2018-ICOHabstracts. 1762}

Aim of special session Young workers are unique. This thoughtprovoking session shows how OSH assessment tools and remediation approaches can be successfully adapted to them.

Presenters: Nicholas Levintow ${ }^{1}$, D.S. Rohlman ${ }^{2}$, C. Pellenq ${ }^{3}$, A. Juárez-García ${ }^{4}$, Ashish Mittal $^{5}$

${ }^{1}$ ILO, Geneva, Switzerland

${ }^{2}$ Occupational and Environmental Health, University of Iowa, Iowa City IA, USA
${ }^{3}$ University of Grenoble-Alpes, France

${ }^{4}$ Universidad Autonoma del Estado de Morelos, Cuernavaca, Morelos, Mexico

${ }^{5}$ Occupational Health and Safety Management Consultancy Services (OHS-MCS), New Delhi, India

\section{4a USING A KAB SURVEY TO IDENTIFY OSH PROJECT PRIORITIES}

Nicholas I Levintow. ILO, Geneva, Switzerland

10.1136/oemed-2018-ICOHabstracts. 1763

Introduction The United States Department of Labour (USDOL)-funded SafeYouth@Work Project aims to promote the safety and health of young workers on the job, with a particular focus on those aged 15-24. Working with key stakeholders, the project works to build tools and capacity to better protect young workers and to sustain a culture of OSH prevention in three 'pilot' countries - Myanmar, the Philippines and Viet Nam.

Among its core objectives, the project seeks to increase knowledge and awareness of the particular OSH hazards and risks faced by young workers. The Project implemented an OSH KAB survey in the pilot countries in late 2016/early 2017. This presentation will describe the KAB study conducted in selected sectors in Myanmar, the Philippines and Viet Nam; the challenges in implementing the survey, key findings, and how the study findings could guide policymakers and stakeholders in building a sustainable culture of $\mathrm{OSH}$ prevention.

Methods Exploratory sequential mixed methods.

Result A well-designed KAB survey can help an OSH project to plan, implement, evaluate and improve its work. A KAB survey gathers information about what respondents know about a subject - here, OSH - as well as how they think employers, labour officials and others should respond to $\mathrm{OSH}$ issues, and what actions they take or fail to take related to $\mathrm{OSH}$.

Discussion A KAB survey on OSH can identify knowledge gaps, beliefs, or patterns that may lead to a better understanding of the challenges to improving OSH compliance. $\mathrm{A} \mathrm{KAB}$ survey can reveal key factors influencing stakeholder attitudes and behaviour on OSH, reasons for those beliefs, and explain why people engage in certain workplace behaviours. An OSH $\mathrm{KAB}$ study can also assess communication tools, platforms and messages to drive OSH prevention. $\mathrm{KAB}$ studies can therefore identify needs, problems and barriers in effective $\mathrm{OSH}$ project delivery, and identify potential approaches to improving the quality and impact of national OSH system functioning.

\section{4b EVOLUTION OF A YOUNG WORKER TRAINING CURRICULUM: TAKING SAFETY FROM THE CLASSROOM TO THE BREAK ROOM}

DS Rohlman. Occupational and Environmental Health, University of lowa, lowa City, IA USA

\subsection{6/oemed-2018-ICOHabstracts. 1764}

Introduction Young Workers (14-24) represent a valuable aspect of the workforce. However, limited work experience and developmental factors predispose young workers to an increased risk of occupational injuries compared to their older counterparts. Although traditional safety training has targeted 